\title{
TEM AND MEP METHODS - APPLICATION EXAMPLES FROM DENMARK
}

\author{
PEDERSEN, F. F. and HALKJAER, $M$. \\ Kemp \& Lauritzen Vand \& Miljø, Michael Drewsensvej 23, DK-8270 Højbjerg \\ Phone +45 8629 1266, Fax +45 8629 9372, e-mail klvmffp@inet.uni-c.dk
}

\begin{abstract}
The TEM and MEP methods are being applied in Denmark. The Danish geology is characterized by thick sedimentary deposits from the quaternary and tertiary period, and in most parts of the country no hard rock is present. The TEM method has been intensively applied for delimitation of aquifers, which often have boundaries of clay with low resistivities. The method have also been applied for general hydrogeological mapping, and surveys for deep saltwater in the aquifers.

Recently the MEP (Multi Electrode Profiling) or CVES method has been applied for more shallow surveys. The method has been applied for very detailed surveys on contaminated sites as well as surveys in larger scale for aquifer vulnerability and delimitation.
\end{abstract}

\section{TEM}

The Transient Electromagnetic (TEM) method was introduced in Denmark about 1990. Previously, the application of this method had mainly been in ore prospecting. Due to thick quaternary and tertiary deposits however, this application is not at all relevant in Denmark (Greenland excepted). The main target for TEM-surveying in Denmark is in the field of aquifer mapping.

In many parts of Denmark the limitation of the sandy aquifers consists of clayey deposits with low resitivities ( 2 to $20 \mathrm{ohm}-\mathrm{m}$ ). The aquifers are often known as "buried valleys", which refers to quaternary or tertiary sand deposited in the previous tertiary landscape. The fact, that boundaries of the aquifers will often be formations with low resistivities, makes the TEM-method a very good tool for mapping the aquifers, as one of the main forces of this metod is the capability of giving a very precise estimate of depth to a good conductor.

The TEM-method has therefore been intensively applied in many parts of Denmark, and has become the most applied tool when it comes to mapping the extent of aquifers. In general the TEM-surveys has been carried out with a Protem 47 as soundings in a central loop configuration with a loop size of $40 \times 40 \mathrm{~m}$. Typically the soundings are made rather dense with an approximate coverage of 16 soundings pr. $\mathrm{km}^{2}$.

Interpretation of TEM-data have been based on 1-dimensional inversion models. 3 to 5 layered models are typical, but multilayered models have also been used. 
For more shallow surveys the MEP-method has recently been introducted. This method is a good supplement to the TEM-method, as it gives very detailed resistivity information in the shallower parts of the geology. The method therefore has been applied for mapping aquifer vulnerabilty (i.e. presence and thickness of clay-layers protecting the aquifer) and detailed mapping on contaminated sites. With respect to mapping of contaminated sites, one of the advantages of the method is the capability to carry out the surveys municipal areas.

As it is a DC-method it is rather unaffected by cultural noise compared to TEM. Electrical installations, however, can affect the measurements if they are nearby the profile.

For MEP-surveying we have used the ABEM - Lund system. The standard equipment comprises instrument, booster and switchbox and $4 \times 100 \mathrm{~m}$ multiconductor cables with take-outs for every $5 \mathrm{~m}$. This system requires a portable $\mathrm{PC}$ to control switchbox and instrument. A maximum of 64 electrodes can be used. Recently instrument, booster and PC has been replaced by the ABEM SAS4000 instrument. Apart from being an integrated instrument, this instrument makes data acquisition faster, and it has 4 separate channels.

A survey for aquifer vulnerability is typically carried out using a configuration with a total length of $400 \mathrm{~m}$. A number af Wenner arrays ranging with electrode spacings from $\mathrm{a}=5 \mathrm{~m}$ to $\mathrm{a}=120 \mathrm{~m}$ are then measured, giving an approximate penetration depth of 60 metres. The data coverage using this configuration is 100 separate measurements pr. 100 metres profile. Daily production in the field applying this configuration is about $1 \mathrm{~km}$.

Compared with DC-profiling methods with shorter array length, one advantage with MEP is the larger penetration depth. For aquifer vulnerability surveys this is important, as the protective clay layers not necessarily are in the upper 15 metres of the geology.

For detailed surveys on contaminated sites, the configuration has been scaled down by a factor 10 , resulting in Wenner arrays ranging from electrode spacings of $a=0.5 \mathrm{~m}$ to $\mathrm{a}=12 \mathrm{~m}$. These surveys have given valuable results when it comes to prepare a program of shallow geotechnical drillings on the site. The short array length of course gives very limited daily field production.

Recently, surveys have been made with an extended configuration at a total length of $800 \mathrm{~m}$. Again, Wenner configurations are used with electrode spacings of up to $a=240 \mathrm{~m}$.

The extended MEP-array will in many situations give all the results in one survey, which earlier required both a TEM and a MEP survey, as penetration depths of more than 100 metres could be expected.

\section{SURVEY EXAMPLE, TEM}

The TEM-method is a valuable tool when it comes to determinination of salt/freshwater interface in or nearby well fields. The profile shown in figure 1 has been made along a series of production wells for groundwater extraction. General geology in the area is moraine clay covering the limestone aquifer. Limestone layers could be expected to larger depths than penetration depth of the TEM-method. 
In limestone with fresh water resistivities higher than $80 \mathrm{ohm}-\mathrm{m}$ could be expected. On the basis of the salt content in the water in different wells, we have interpreted the low resistivities in deepest parts of the profile as originating in high salt content in the limestone-aquifer. The central upconing of low resistivities on the profile therefore reflects wells with saltwater near the intake.

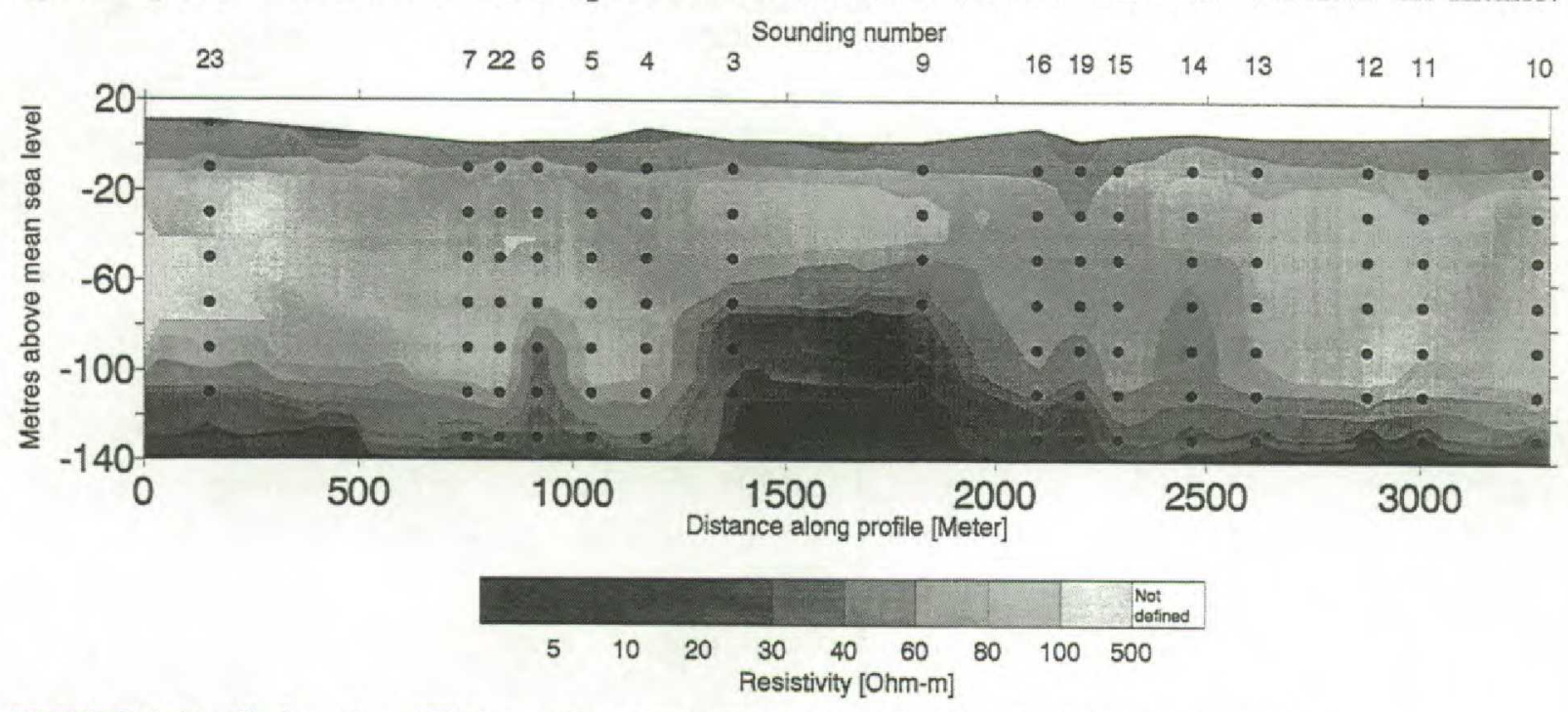

FIGURE 1: Profile based on TEM-soundings from survey in wellfield with saltwater intrusion.

Based on information from the TEM-survey, it is possible for the water supply to avoid or reduce use of the wells in the area with upconing saltwater.

\section{SURVEY EXAMPLE, MEP}

The shown profile in figure 2 is from a survey for a new wellfield for one of Denmarks larger water supplys. Data are acquired with an extended MEP-array, and electrode spacings has been in the range from $\mathrm{a}=10 \mathrm{~m}$ to $\mathrm{a}=240 \mathrm{~m}$. Field data are inverted using RES2DINV (Loke, M.H.), and the inversion reveals details that could not be seen on the measured data.

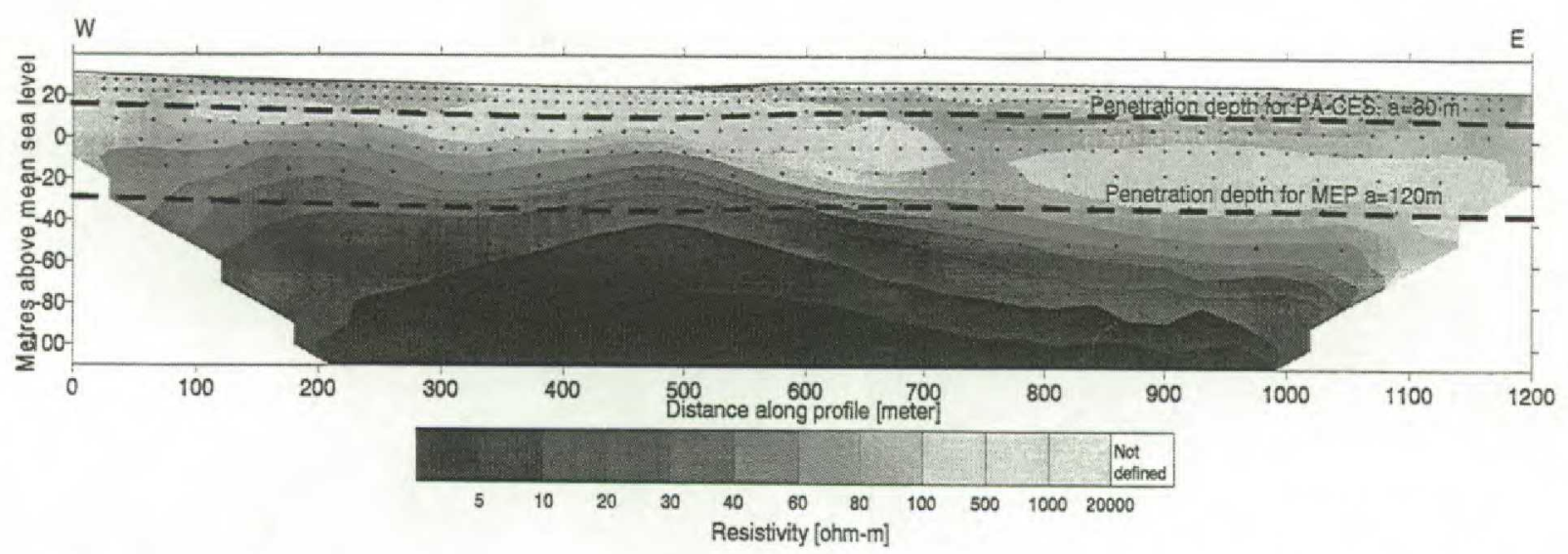

FIGURE 2: Extended MEP-profile with Wenner-arrays up to $a=240 \mathrm{~m}$. The profile is from a survey for aquifer extent and vulnerability.

The geological interpretation of the profile is combined with geological information from wells nearby. Resistivities in the upper part of geology higher than $80 \mathrm{ohm}-\mathrm{m}$ are interpreted as aeolianor diluvial sand, resistivities below $60 \mathrm{ohm}-\mathrm{m}$ as diluvial clay. In levels from terrain and to 10 metres the upper part of the aquifer is seen. Resistivites in the range from 80 to $200 \mathrm{ohmm}$ are 
reflecting the diluvial sand aquifer. The lower limitation of the aquifer is seen in resistivities lower than $60 \mathrm{ohmm}$, which can be interpreted as late glacial- or diluvial clay.

The profile shows that the aquifer in the western end is shallow and vulnerable, while it is. deeper in the eastern end, and has some protection. Furthermore, the profile has given information on extent of the aquifer. I can be seen, that this information on the lower limitation of the aquifer in the eastern part had not been acquired if the shorter array lenghts had been used. On the basis of this and other profiles, advise on most suitable areas for new wells could be given to the water supply.

\section{INTERPRETATIONAL AND PRACTICAL PROBLEMS}

When applying the methods according to Danish conditions, lithologies with same resistivity, but very different properties can sometimes lead to misinterpretations. One problem here is the resistivity equivalence between sand/gravel formations and silty formations. The more sandy formations can often serve as good aquifers, while water extraction from silty formations can be more or less impossible.

One main problem with the TEM-method is its noise-sensitivity. This is especially a problem when working in areas where no good conductors are present in the ground, and signals therefore are weak. We have experienced, that if a good conductor is present, the TEM-method can in some occasions be applied with success even in municipal areas.

\section{FUTURE DEVELOPMENTS}

For the TEM-method it is desirable to have higher momentum in the transmitter loop at the same size or less of the currently used loop. This will give increase penetration depths without making the field process more troublesome.

For the MEP-method 3-dimensional data-acquisition would be a obvious development. This could provide very detailed information when surveying contaminated sites. There is a lack of good tools for presentation of data with a 3-dimensional spatial distribution, so hopefully, in the future we will see better presentations with 3-dimensional animated fence-diagrams for spatial presentation of MEP-data. 